\title{
Maternal glucocorticoid treatment modulates placental leptin and leptin receptor expression and materno-fetal leptin physiology during late pregnancy, and elicits hypertension associated with hyperleptinaemia in the early-growth-retarded adult offspring
}

\author{
Mary C Sugden, Maria L Langdown, Melinda J Munns and Mark J Holness \\ Department of Diabetes and Metabolic Medicine, Division of General and Developmental Medicine, St Bartholomew's and the Royal London School of
} Medicine and Dentistry, Queen Mary, University of London, London, UK

(Correspondence should be addressed to M J Holness, Department of Diabetes and Metabolic Medicine, Medical Sciences Building, Queen Mary, University of London, Mile End Road, London E1 4NS, UK; Email: m.j.holness@qmw.ac.uk)

\begin{abstract}
Background: Leptin concentrations are increased during late pregnancy, and leptin receptors are expressed in placental and fetal tissues, suggesting a role for leptin in placental and/or fetal growth, or both. In humans, leptin concentrations in adulthood are inversely related to body weight at birth, independent of adult adiposity, and correlate with fasting insulin. Glucocorticoids and insulin regulate leptin secretion. Excessive exposure to glucocorticoids during late fetal development in the rat causes intrauterine growth retardation (IUGR), together with hypertension and hyperinsulinaemia in adulthood. Leptin may have a role in the development of some forms of hypertension.

Objective: To determine whether IUGR induced by maternal glucocorticoid treatment during the last third of pregnancy in the rat is associated with modulation of either maternal or fetal leptin concentrations, the placental expression of leptin or the short form of the leptin receptor (ObR-S), or combinations thereof, and to evaluate whether hypertension or hyperinsulinaemia in the earlygrowth-retarded adult progeny of dexamethasone-treated dams is associated with altered leptin concentrations.

Design and Methods: Dexamethasone was administered to pregnant rats from day 15 to day 21 of gestation via a chronically implanted subcutaneous osmotic minipump. Protein expression of leptin and ObR-S in the placenta at day 21 of pregnancy was measured by western blotting. Plasma leptin and insulin concentrations were determined by radioimmunoassay and ELISA respectively. Systolic hypertension was measured by tail cuff plethysmography.

Results: Dexamethasone administration during the last third of pregnancy decreased placental mass and fetal body weight at day 21 of gestation, caused maternal hyperleptinaemia but fetal hypoleptinaemia, and suppressed placental leptin protein expression whilst up-regulating placental protein expression of ObR-S. The male and female offspring of dexamethasone-treated dams were hypertensive from 12 weeks of age. One-year-old offspring of dexamethasone-treated dams exhibited significant hyperleptinaemia compared with age-matched controls, an effect associated with hyperinsulinaemia in the male, but not female, offspring.

Conclusions: The rat model of maternal dexamethasone treatment is established as a paradigm of 'programmed' hypertension in man. Our data show modification of placental leptin and leptin receptor protein expression by dexamethasone treatment during the last third of pregnancy. We also show that leptin concentrations are suppressed during fetal life but increased in adulthood in this rat model of programmed hypertension. Our data do not necessarily establish a causal relationship between fetal hypoleptinaemia and impaired fetal growth during early life, or between hyperleptinaemia and hypertension in adulthood. Nevertheless, they suggest that hyperleptinaemia may be a component of the cluster of metabolic abnormalities seen in the insulin resistance syndrome in man. They also suggest that excessive fetal exposure to glucocorticoids could be a common earlylife stimulus to the association between hyperinsulinaemia, hypertension and hyperleptinaemia often seen in individuals of low birthweight.
\end{abstract}

European Journal of Endocrinology 145 529-539 


\section{Introduction}

Leptin acts as an afferent satiety hormone, regulating appetite, body weight gain and fat deposition $(1,2$; reviewed in 3) via a negative feedback loop involving receptors in the hypothalamus $(2,4)$. In addition, increased circulating concentrations of leptin are found during late pregnancy both in women and in animal models. In humans, plasma leptin concentrations are increased significantly (by approximately 2.7-fold) during the second trimester of pregnancy and remain high during the third trimester, decreasing around birth $(5,6)$. Comparable increases in maternal leptin concentrations are observed in the rat, in which maternal plasma leptin concentrations during late pregnancy are increased by approximately twofold compared with those found in the non-pregnant state (7). In the mouse, the animal model most frequently used for studies of the potential roles of leptin during pregnancy, leptin concentrations in the maternal circulation increase even more dramatically (25-fold) during late pregnancy (8). Findings of increased leptin concentrations during late pregnancy $(5,6,9)$ and the expression of leptin receptors in a range of fetal tissues (10) have raised the possibility that increased leptin concentrations during pregnancy perform a physiological function.

Leptin protein concentrations in human umbilical cord blood positively correlate with body weight and adiposity at birth, suggesting a potential role in fetal and adipose tissue development (11-14). However, leptin replacement therapy has permitted successful matings between $o b / o b$ female mice and $o b / o b$ males (15), and leptin withdrawal at various stages of the pregnancy does not appear to influence offspring growth and viability (16). Such findings indicate that high maternal leptin concentrations are not vital for fetal development and argue against an obligatory role for leptin in modulating fetal growth. However, several of six alternatively spliced forms of mRNA for the leptin receptor $(\mathrm{ObR})$ have been identified in the mouse placenta. These include the short form of the leptin receptor, ObR-S (the proposed transport form of the receptor) $(10,17)$, and the long form of the leptin receptor, ObR-L (the proposed signalling form of the leptin receptor) (18). In human pregnancies, maternal plasma leptin concentrations negatively correlate with placental weight at term (11). The possibility is therefore raised that leptin could influence placental growth and development or function, or both.

Although the precise role of leptin as a fetal growth factor remains unresolved, two independent studies have shown that blood concentrations of leptin in adulthood may be related to body weight at birth, independent of adult adiposity $(19,20)$. The negative relationships between birthweight and subsequent leptin production in adulthood are the opposite of the reported positive correlations seen between body weight and leptin production in fetuses (21) and infants (11-14). Maternal nutrition during pregnancy influences the body weight of the fetus (22-24) and, in female pigs, plasma leptin concentrations are higher in progeny from mothers provided with more feed (25). In this last study, although maternal nutrition did not affect mean body weight at birth, there was a negative relationship between body weight at birth and measures of leptin production in adulthood (25). Hormonal influences may also be important. Glucocorticoids have an important role in normal fetal development and, in many instances, are important for the maturation of fetal tissues in preparation for extra-uterine life (reviewed in 26). However, fetal exposure to excess glucocorticoids has been implicated as a causative factor in fetal growth retardation (reviewed in 27, 28). Moreover, fetal cortisol concentrations are increased in human intrauterine growth retardation (29). The influence of glucocorticoids on maternal and fetal leptin concentrations in relation to fetal growth retardation is unknown.

The fetus is normally protected from the higher maternal concentrations of glucocorticoids by the placental enzyme $11 \beta$-hydroxysteroid dehydrogenase type-2 (11 $\beta$-HSD-2), which is highly expressed in the placental syncytiotrophoblast (30) and catalyses the rapid conversion of active glucocorticoids to inert 11keto derivatives (i.e. cortisol to cortisone in humans and corticosterone to 11 dehydrocorticosterone in rats). The synthetic glucocorticoid dexamethasone is a poor substrate for $11 \beta$-HSD-2 $(30,31)$ and, in the rat, dexamethasone administration during the last third of pregnancy leads to fetal growth retardation (reviewed in 27, 28). Early growth retardation induced by maternal dexamethasone treatment produces fasting and post-glucose hyperinsulinaemia (32) and hypertension (33) in the adult offspring. Hyperinsulinaemia is often associated with hyperleptinaemia (3437). Emerging evidence suggests a physiological role for leptin in maintaining arterial blood pressure (38). Furthermore, blood pressure is increased in transgenic skinny mice and obese $\mathrm{KKA}^{y}$ mice, both of which are hyperleptinaemic (39). In man, increased leptin concentrations have been suggested to contribute to the aetiology of essential hypertension (40). In the present study, we tested the hypothesis that the intrauterine growth retardation induced by maternal glucocorticoid treatment during the last third of pregnancy in the rat might be associated with modulation of either maternal or fetal leptin concentrations or the placental expression of leptin or ObR-S, and whether the effect of maternal dexamethasone treatment to programme hypertension and hyperinsulinaemia in the adult progeny is associated with modulation of plasma leptin concentrations. 


\section{Materials and methods}

\section{Materials}

Female Wistar rats were obtained from Charles River Ltd, Margate, Kent, UK. All organic solvents were of analytical grade and obtained from BDH Laboratories Supplies, Poole, Dorset, UK. Other biochemicals and chemicals, including glucose assay kits, were from Boehringer Corporation, Lewes, East Sussex, UK or from Sigma Chemical Corporation, Poole, Dorset, UK, with the following exceptions. Plasma leptin was measured using kits from Linco Research, St Louis, MO, USA. Kits for determination of plasma insulin concentrations by ELISA were from Mercodia, Uppsala, Sweden. Reagents for enhanced chemiluminescence (ECL) detection and anti-rabbit secondary antibody were purchased from Amersham Pharmacia Biotech, Little Chalfont, Buckinghamshire, UK. Anti-leptin (Y-20, Santa Cruz Biotechnology) rabbit polyclonal antibody, anti-ObR (K-20, Santa Cruz Biotechnology), goat polyclonal antibody and anti-goat secondary antibody were purchased from Insight Biotechnology Ltd (Wembley, Middlesex, UK). Dexamethasone (sodium phosphate) was obtained from David Bull Laboratories, Warwick, Warwickshire, UK. Mini-osmotic pumps were purchased from Charles River Ltd, Margate, Kent, UK

\section{Animals}

All studies were conducted in adherence to the regulation of the United Kingdom Animal Scientific Procedures Act (1986). Female Wistar rats weighing 200-250 g were subjected to a standard light (0800$2000 \mathrm{~h})$-darkness $(2000-0800 \mathrm{~h})$ cycle in a temperature-controlled room $\left(21 \pm 2{ }^{\circ} \mathrm{C}\right)$. The rats were housed in individual cages and were given free access to food and water. Rats were maintained on standard, pelleted rodent diet purchased from Charles River. This diet consisted of $52 \%$ carbohydrate, $15 \%$ protein, $3 \%$ lipid and 30\% non-digestible residue (by weight), and contained $10.96 \mathrm{~kJ}$ metabolisable energy/g. Rats were time-mated by the appearance of sperm plugs (day 0 of pregnancy) (41).

Dexamethasone was administered from day 15 of gestation via chronically implanted subcutaneous osmotic minipumps at doses of 100, 200 or $400 \mu \mathrm{g} / \mathrm{kg}$ maternal body weight per day, as specified. The lowest dosage is that used previously to elicit hypertension and post-glucose hyperinsulinaemia in the adult offspring $(32,33)$. The procedure used in the present experiments differs from that used previously in that we infused dexamethasone at a steady rate, whereas in the previous studies it was administered daily via a single bolus injection $(32,33)$. An initial priming dose $(0.1 \mathrm{mg})$ of dexamethasone was given by subcutaneous injection before minipump implantation.
Sham operations involving incision and manipulation under anaesthesia identical to the procedure for implantation of the osmotic minipump were undertaken on control pregnant rats. Dams and fetuses were studied on day 21 of pregnancy. In total, there were seven control dams, and 14 dexamethasone-treated dams, of which seven and five were administered dexamethasone at a dose of 100 or $200 \mu \mathrm{g} / \mathrm{kg}$ maternal body weight per day respectively. Because of poor tolerance, only two dams were administered dexamethasone at the highest dose $(400 \mu \mathrm{g} / \mathrm{kg}$ maternal body weight per day) and this procedure was discontinued. Our procedure led to almost total suppression of endogenous corticosterone concentrations both in the dam and the 21-day-old fetus even at the lowest dose (results not shown).

For studies of the persistent effects of maternal dexamethasone treatment on leptin concentrations during postnatal life, dexamethasone was administered at the lowest dose only $(100 \mu \mathrm{g} / \mathrm{kg}$ body weight per day), as this dose was shown in pilot studies to elicit significant fetal growth retardation in the absence of adverse effects on fetal number or viability. To avoid handling stress and anaesthesia, the minipumps, which were set to deliver a fixed volume that was exhausted after 7 days, were not removed from the dams after parturition. Undue stress immediately post partum can lead to abandonment of the litter, as well as to interrupted suckling over a critical developmental period. Litters containing fewer than 10 pups or more than 15 pups were excluded from the study. The male and female offspring of control and dexamethasonetreated dams were separated at 26 days after birth, and the offspring weaned on to standard, pelleted rodent diet. Male and female offspring of control and dexamethasone-treated dams were studied at intervals up to 1 year of age. Each data group was comprised of rats from at least three separate litters. In total, 12 offspring of control dams and eight offspring of dexamethasone-treated dams were studied.

\section{Tissue and blood sampling}

Rats were anaesthetised by intraperitoneal injection of sodium pentobarbitone $(60 \mathrm{mg} / \mathrm{ml}$ in $0.9 \% \mathrm{NaCl}$; $1 \mathrm{ml} / \mathrm{kg}$ body weight). Once locomotor activity had ceased, three whole placentas from individual animals were rapidly excised, amniotic membranes were removed and placentas were freeze-clamped in liquid nitrogen using precooled aluminium tongs. Frozen placental samples were wrapped individually in aluminium foil and stored in liquid nitrogen. Plasma was obtained from whole blood sampled from the chest cavity after the removal of the heart, and stored at $-20{ }^{\circ} \mathrm{C}$ until required for analysis. 


\section{Western blotting}

Placental samples (approximately $100 \mathrm{mg}$ ) were homogenised using a Polytron Tissue homogeniser (PT 10 probe; position $5,15 \mathrm{~s}$ ) in $1 \mathrm{ml}$ ice-cold extraction buffer A: $20 \mathrm{mmol} / \mathrm{l}$ Tris, $137 \mathrm{mmol} / \mathrm{l} \mathrm{NaCl}$, $2.7 \mathrm{mmol} / \mathrm{l} \mathrm{KCl}, 1 \mathrm{mmol} / \mathrm{l} \mathrm{CaCl}_{2}, 10 \%$ glycerol, $1 \%$ Igepal, $45 \mathrm{mmol} / \mathrm{l}$ sodium orthovanadate $\left(\mathrm{Na}_{3} \mathrm{VO}_{4}\right.$, $0.2 \mathrm{mmol} / \mathrm{l}$ phenyl methylsulphonyl fluoride, $10 \mu \mathrm{g} / \mathrm{ml}$ leupeptin, $1.5 \mathrm{mg} / \mathrm{ml}$ benzamidine, $50 \mu \mathrm{g} / \mathrm{ml}$ aprotinin, $50 \mu \mathrm{g} / \mathrm{ml}$ pepstatin A (in DMSO), pH 8.0. Homogenates were placed on ice for $20 \mathrm{~min}$, centrifuged in an Eppendorf centrifuge (12 000 r.p.m. for $20 \mathrm{~min}$. at $4{ }^{\circ} \mathrm{C}$ ) and the supernatants stored at $-20{ }^{\circ} \mathrm{C}$ until required for analysis. Samples (20$30 \mu \mathrm{g}$ of total protein) were subjected to SDS-PAGE using a $12 \%$ (leptin) or $9 \%$ (leptin receptor) resolving gel, with a $6 \%$ stacking gel. After SDS-electrophoresis, resolved proteins were transferred electrophoretically to nitrocellulose membranes, and then blocked for $2 \mathrm{~h}$ at room temperature (Tris-buffered saline (TBS) supplemented with $0.05 \%$ Tween (TBST) and $5 \%(\mathrm{w} / \mathrm{v})$ nonfat powdered milk). The nitrocellulose blots were incubated overnight at $4{ }^{\circ} \mathrm{C}$ with polyclonal antisera raised against leptin or the leptin receptor (1:200 dilution), washed with $0.05 \%$ Tween in TBS $(3 \times$ $5 \mathrm{~min}$ ) and incubated with the horseradish peroxidaselinked secondary antibody IgG anti-rabbit (1:2000) or horseradish peroxidase-linked secondary antibody IgG anti-goat $(1: 20000)$, in $1 \%(\mathrm{w} / \mathrm{v})$ non-fat milk in TBST) for 1 or $2 \mathrm{~h}$ respectively at room temperature. Bound antibody was visualised using ECL according to the manufacturer's instructions. The blots were then exposed to Hyperfilm and the signals quantified by scanning densitometry and analysed with Molecular Analyst software (Biorad Ltd, Hemel Hempstead, Herts, UK). An initial characterisation using competing antigenic peptides was performed to determine the specificity of the antibodies. The specific protein bands were identified by their specific reduction in immunoreactivity when competing peptide was included. The amounts of extracts loaded on to the gel were varied to establish that the relative densities of the bands corresponding to the proteins were linear with concentration. Immunoblots were performed under conditions in which autoradiographic detection was in the linear response range. For each panel, the results are from a single gel exposed for a uniform duration.

\section{Biochemical and physiological determinations}

Plasma insulin concentrations were measured by ELISA using rat insulin standards (Mercodia). Plasma leptin concentrations were determined by a commercially available RIA using rat leptin standards (Rat Leptin RIA Kit, Linco Research). Systolic blood pressures were determined by tail cuff plethysmography at room temperature in lightly anaesthetised rats (sodium pentobarbitone; $100 \mu \mathrm{g} / 300 \mathrm{~g}$ body weight). All measurements were taken in the morning and each rat had five blood pressure traces recorded in a single session. The coefficient of variation was $3.2 \%$.

\section{Statistical analyses}

Statistical comparisons were made with StatView (Abacus Concepts Inc., Berkeley, CA, USA). Multiple comparisons were made by analysis of variance (ANOVA) and individual comparisons by Fisher post hoc tests. Comparisons between just two sets of data were performed with the unpaired Student's $t$-test. The criterion for significance was set at $P<0.05$. All data are presented as the means \pm S.E.M.

\section{Results}

\section{Maternal dexamethasone treatment during pregnancy in the rat decreases maternal body weight without influencing maternal food intake}

Maternal dexamethasone administration at a dose of either 100 or $200 \mu \mathrm{g} / \mathrm{kg}$ body weight during the last third of pregnancy (from day 15) led to a $17 \%$ $(P<0.05)$ or $23 \%(P<0.01)$ decrease in maternal body weight at day 21 of gestation (Fig. 1A). Dexamethasone administration did not alter duration of gestation or the number or viability of offspring (results not shown). No further decline in maternal body
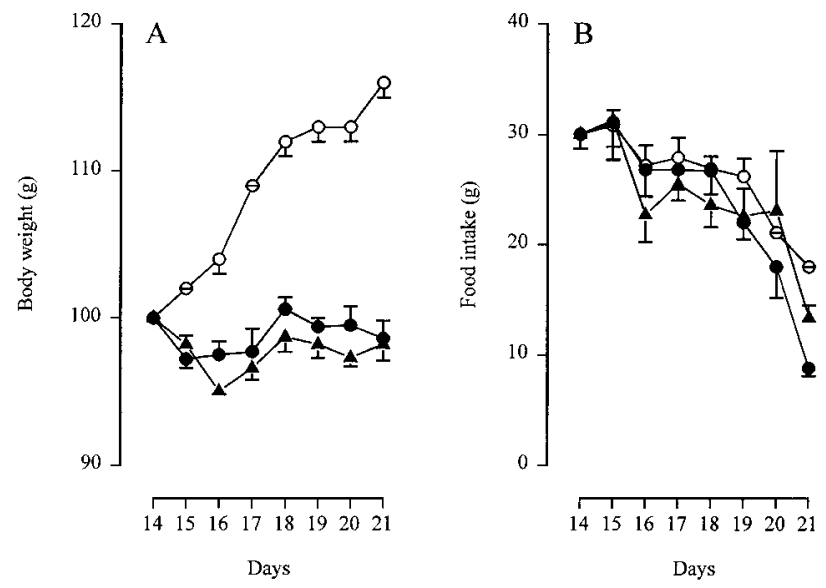

Figure 1 Body weights and food intakes in control pregnant rats $(O)$ and pregnant rats treated with dexamethasone at doses of $100 \mu \mathrm{g} / \mathrm{kg}$ maternal body weight per day (๑) or $200 \mu \mathrm{g} / \mathrm{kg}$ maternal body weight per day ( $\mathbf{\Lambda})$ from day 15 of pregnancy. Results are presented as means \pm S.E.M. for five to seven rats. Dexamethasone administration at both doses significantly impaired body weight gain at all time points $(P<0.05)$. There were no statistically significant effects of dexamethasone treatment on food intake. 
weight occurred when the dexamethasone dose was increased to $400 \mu \mathrm{g} / \mathrm{kg}$ maternal body weight, but offspring viability decreased (results not shown). This procedure was therefore discontinued. Suppression of maternal body weight by dexamethasone administration occurred in the absence of any marked decline in maternal food intake relative to control; the normal decline in maternal food intake occurring during the last few days of pregnancy (term $=23$ days) was observed in all three groups (Fig. 1B).

\section{Maternal dexamethasone treatment during pregnancy in the rat impairs fetal growth}

We confirmed that prenatal exposure to dexamethasone leads to fetal intrauterine growth retardation, as reported previously when dexamethasone was administered daily as a bolus (42). The effect of maternal dexamethasone administration was dose dependent. As seen in Fig. 2A, maternal dexamethasone administration at a dose of 100 or $200 \mu \mathrm{g} / \mathrm{kg}$ body weight from day 15 of gestation led respectively to an $8.9 \%$ $(P<0.01)$ and a $28.7 \%(P<0.001)$ decrease in fetal body weight at day 21 of gestation.

\section{Maternal dexamethasone treatment during late pregnancy in the rat decreases placental weights}

Placental weight at day 21 of gestation was also significantly decreased in a dose dependent manner by dexamethasone treatment from day 15 of gestation (Fig. 2B). Placental weight was decreased by $27 \%$

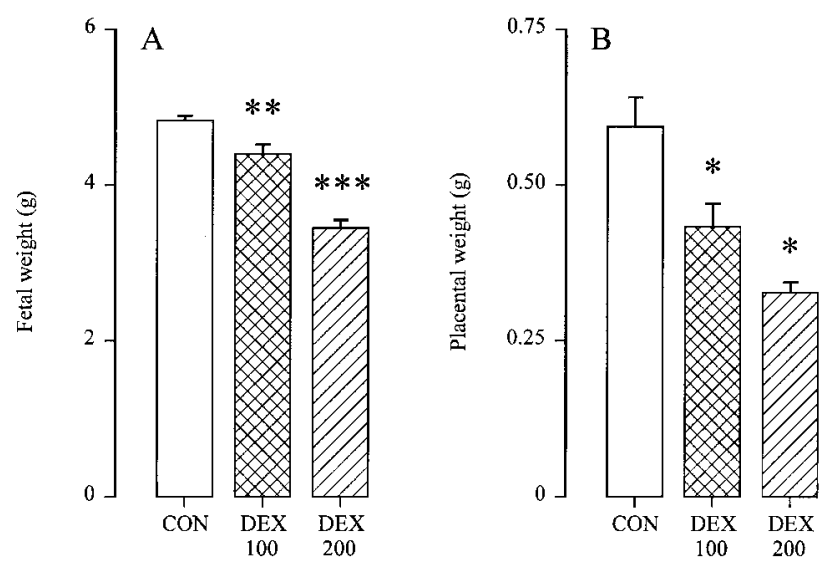

Figure 2 Fetal and placental weights of 21-day-old control pregnant rats (CON; open bars) and 21-day-old pregnant rats administered dexamethasone at doses of $100 \mu \mathrm{g} / \mathrm{kg}$ maternal body weight per day (DEX 100; latticed bars) or $200 \mu \mathrm{g} / \mathrm{kg}$ maternal body weight per day (DEX 200; hatched bars) from day 15 of pregnancy. Results are presented as means \pm S.E.M. for five to seven rats (dams) or four litters (fetuses). Statistically significant effects of maternal dexamethasone administration: ${ }^{\star} P<0.05$; ${ }^{\star \star} P<0.01 ;{ }^{\star \star \star} P<0.001$.
$(P<0.05)$ at the lower dexamethasone dose $(100$ $\mu \mathrm{g} / \mathrm{kg}$ body weight $)$ and by $45 \%(P<0.05)$ at the higher dose $(200 \mu \mathrm{g} / \mathrm{kg}$ body weight). Thus the percentage decline in placental weight (when expressed relative to the percentage decline in fetal body weight) was independent of dexamethasone dose but, irrespective of dose, exceeded that of the fetus.

\section{Maternal leptin concentrations are increased in a dose-dependent manner by dexamethasone administration}

Maternal plasma leptin concentrations at day 21 of gestation tended to be greater (by 1.6-fold) in the pregnant group treated with dexamethasone at $100 \mu \mathrm{g} / 100 \mathrm{~g}$ body weight, and were significantly higher (by 3.9-fold, $P<0.01$ ) as a result of dexamethasone treatment at the higher dose (Fig. 3A). The increases in circulating leptin concentrations were observed in the absence of increases in adipose tissue mass, assessed by visual inspection. In a limited number of further experiments, we observed that increasing the dexamethasone dose to $400 \mu \mathrm{g} / \mathrm{kg}$ body weight massively increased maternal leptin concentrations (to $28.5 \pm 2.5 \mathrm{ng} / \mathrm{ml} ; n=2$ ), but these experiments were discontinued because of poor tolerance (see above).

\section{Fetal leptin concentrations are suppressed by maternal dexamethasone treatment}

Fetal plasma leptin concentrations were considerably lower than those of the dams (note change of scale)
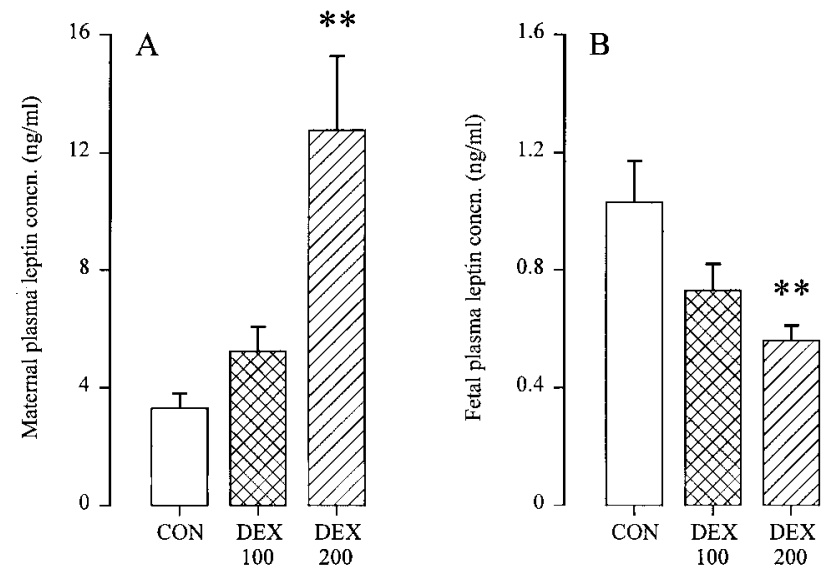

Figure 3 Maternal and fetal circulating leptin concentrations of 21day-old control pregnant rats (CON; open bars) and 21-day-old pregnant rats administered dexamethasone at a dose of $100 \mu \mathrm{g} / \mathrm{kg}$ maternal body weight per day (DEX 100; latticed bars) or 200 $\mu \mathrm{g} / \mathrm{kg}$ maternal body weight per day (DEX 200; hatched bars) from day 15 of pregnancy. Results are presented as means \pm S.E.M. for five to seven rats (dams) or four litters (fetuses). Statistically significant effects of maternal dexamethasone administration: ${ }^{\star *} P<0.01$ 

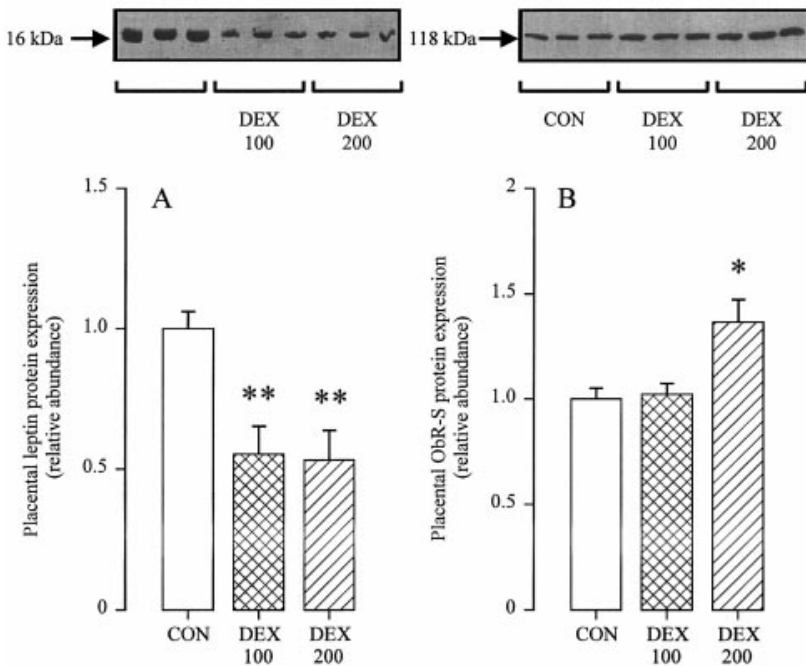

Figure 4 Leptin and ObR-S protein expression in placentas of 21day-old control pregnant rats (CON; open bars) and 21-day-old pregnant rats administered dexamethasone at doses of $100 \mu \mathrm{g} / \mathrm{kg}$ maternal body weight per day (DEX 100; latticed bars) or 200 $\mu \mathrm{g} / \mathrm{kg}$ maternal body weight per day (DEX 200; hatched bars) from day 15 of pregnancy. Results are presented as means \pm S.E.M. for three to seven rats. Statistically significant effects of maternal dexamethasone administration: ${ }^{*} P<0.05 ;{ }^{*} P<0.01$.

and, contrasting with the maternal response, were decreased in a dose-dependent manner by maternal dexamethasone treatment (Fig. 3B) and achieved significance at the higher dexamethasone dose $(46 \%$ decline, $P<0.01)$.

\section{Maternal dexamethasone treatment during pregnancy in the rat down-regulates placental leptin expression at day 21 of gestation}

In control rats, placental leptin was immunodetectable as a band corresponding to $16 \mathrm{kDa}$ (Fig. 4). Placental leptin protein expression in late pregnancy (day 21) was significantly decreased (by $47 \%, P<0.01$ ) by maternal dexamethasone treatment at a dose of $100 \mu \mathrm{g} / \mathrm{kg}$ body weight. Increasing the dose to $200 \mu \mathrm{g} / \mathrm{kg}$ body weight per day did not further suppress placental leptin protein expression.

\section{Protein expression of ObR-S is up-regulated by maternal dexamethasone treatment in the 21-day-old placenta}

We also analysed the effect of dexamethasone on the placental protein expression of ObR-S in the 21-day-old pregnant rat. By western blotting, we detected an immunoreactive band at approximately $118 \mathrm{kDa}$ using the short-form specific (ObR K-20, Santa Cruz Biotechnology) leptin receptor antibody (see also (43)). This was the only major band detected. Although dexamethasone at the lower dose did not significantly influence placental ObR-S protein expression at day 21 of gestation, dexamethasone at a dose of $200 \mu \mathrm{g} / \mathrm{kg}$ maternal body weight selectively up-regulated placental ObR-S (36\%, $P<0.05)$ (Fig. 4B).

\section{Maternal dexamethasone treatment during pregnancy leads to hypertension in adulthood}

In control offspring, systolic blood pressure increased with age in both male and female groups, but effects of ageing to increase systolic blood pressure were greater in the male group (results not shown). Systolic blood pressure was significantly higher in offspring of dexamethasone-treated dams compared with control offspring at 3 months of age in both male and female offspring $(+26 \%$ and $+25 \%$ respectively; $P<0.05)$. This effect persisted at 6 months of age in both male and female offspring $(+25 \%$ and $+15 \%$ respectively; $P<0.05)$. Systolic blood pressures at 1 year of age are shown in Fig. 5. Both male and female offspring of dexamethasone-treated dams exhibited significant systolic hypertension compared with control offspring $(P<0.01$ and $P<0.001$ respectively $)$.

\section{Maternal dexamethasone treatment during pregnancy leads to hyperleptinaemia in adult (1-year-old) offspring}

In control offspring, plasma leptin concentrations increased with age in both male and female groups,

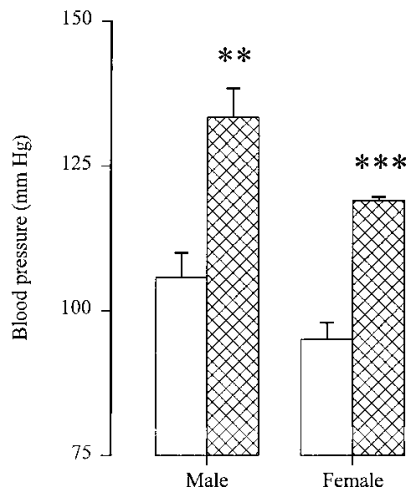

Figure 5 Systolic blood pressure in 1-year-old early-growthretarded offspring of dexamethasone-treated dams. Systolic blood pressure was measured in 1-year-old male and female offspring of dams treated with dexamethasone at a dose of $100 \mu \mathrm{g} / \mathrm{kg}$ maternal body weight per day from day 15 of pregnancy (latticed bars) and age-matched control offspring (open bars). Systolic blood pressures were determined by tail cuff plethysmography at room temperature in lightly anaethetised rats. All measurements were undertaken in the morning, and each rat had five blood pressure traces recorded in a single session. Results are means \pm S.E.M. for three to seven rats per group. Statistically significant effects of maternal dexamethasone treatment: ${ }^{* \star} P<0.01$; ${ }^{\star \star \star} P<0.001$. 
but effects of ageing in increasing plasma leptin concentrations were greater in the male group. As a consequence, plasma leptin concentrations tended to be greater in the rats at 3 months of age and were 3.2fold higher $(P<0.05)$ at 6 months of age in male than in female control offspring. In rats at 1 year of age, plasma leptin concentrations were 2.3 -fold $(P<0.01)$ greater in male than in female control offspring (Fig. 6A). Leptin concentrations did not differ significantly between control offspring and offspring of dexamethasone-treated dams at any of the time points examined up to 6 months of age. However, by 1 year of age, both male and female offspring of dexamethasonetreated dams exhibited increased plasma leptin concentrations compared with control offspring (1.6- and 2.3-fold increases respectively; $P<0.05$ in both cases) (Fig. 6A). Measurement of adipose tissue weights of representative depots of male (epidydymal) and female (parametrial) control offspring and offspring of dexamethasone-treated dams indicated that hyperleptinaemia in male and female offspring of dexamethasone-treated dams was not a consequence of increased adiposity. Epidydymal adipose tissue fat mass of male rats was significantly decreased (by 59\%; $P<0.001$ ) in offspring of dexamethasone-treated dams (control, 7.4 $0.5 \mathrm{~g}$; dexamethasone, $3.1 \pm 0.7 \mathrm{~g}$ ), whereas parametrial fat mass of female rats did not differ significantly between control offspring and offspring of dexamethasone-treated dams (control, 3.9 $0.5 \mathrm{~g}$; dexamethasone, $3.0 \pm 0.3 \mathrm{~g}$ ).

\section{Maternal dexamethasone treatment during pregnancy increases ambient plasma insulin concentrations in male offspring during maturation and in adulthood}

There were no obvious sex differences in plasma insulin concentrations during the first 3 months of post-natal life in either control offspring or offspring of dexamethasone-treated dams. However, by 6 months of age plasma insulin concentrations were significantly greater in the male than in female control offspring (by 1.6-fold; $P<0.05)$ and offspring of dexamethasone-treated dams (by 1.7-fold; $P<0.01$ ). In addition, the male offspring of dexamethasone-treated dams had developed significant ambient hyperinsulinaemia, compared with age-matched control offspring, by 6 months of age (by 2.1-fold; $P<0.001$ ). In female offspring of dexamethasone-treated dams, plasma insulin concentrations were also significantly increased (1.9-fold; $P<0.05)$ compared with age-matched controls by 6 months of age. At 1 year of age, plasma insulin concentrations were significantly higher (by 3.7-fold; $P<0.001$ ) in the male versus female offspring of dexamethasone-treated dams, but not in control offspring (Fig. 6B). The male offspring of dexamethasone-treated dams maintained significant ambient hyperinsulinaemia, compared with
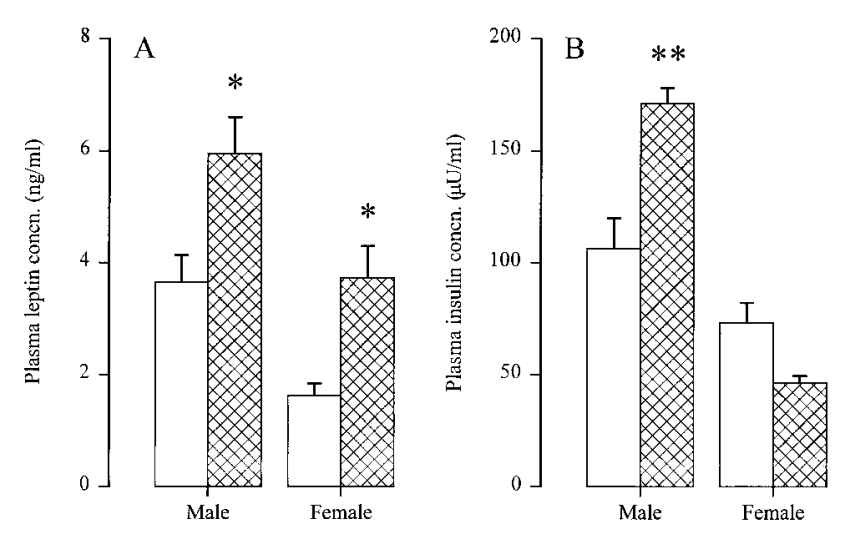

Figure 6 Plasma leptin and insulin concentrations in 1-year-old early-growth-retarded offspring of dexamethasone-treated dams. Leptin and insulin concentrations were measured in plasma of 1 -year-old male and female offspring of dams treated with dexamethasone at a dose of $100 \mu \mathrm{g} / \mathrm{kg}$ maternal body weight per day from day 15 of pregnancy (latticed bars) and age-matched control offspring (open bars). Results are means \pm S.E.M. for three to seven rats per group. Statistically significant effects of maternal dexamethasone treatment: ${ }^{\star} P<0.05 ;{ }^{\star \star} P<0.01$.

age-matched control offspring, at 1 year of age (by 1.6 fold; $P<0.05$ ), but this effect was no longer observed in female offspring of dexamethasone-treated dams at 1 year of age (Fig. 6B).

\section{Discussion}

This study has demonstrated that the fetal growth retardation elicited by dexamethasone administration during the last third of pregnancy in the rat is associated with decreased placental mass and fetal body weight at day 21 of gestation, together with maternal hyperleptinaemia but fetal hypoleptinaemia, and suppression of placental leptin protein expression in the face of modest up-regulation of placental ObR-S protein expression. Dexamethasone administration during the last third of pregnancy led to hypertension in the adult progeny, which was significant from 12 weeks of age and observed in both male and female offspring. It also resulted in significant hyperleptinaemia in 1-year-old male and female offspring, an effect associated with hyperinsulinaemia in the 1-year-old male, but not female, offspring of dexamethasonetreated dams.

The present study demonstrates that maternal leptin concentrations at day 21 of pregnancy are upregulated in a dose-dependent manner by chronic exposure to dexamethasone for the preceding 7 days. Increased leptin concentrations are not associated with a decreased daily food intake by the dexamethasonetreated dams compared with control. This suggests that, within the context of mid-to-late pregnancy, a decline (rather than an increase) in leptin concentrations is the primary regulatory stimulus for modulation 
of appetite (i.e., satiety mechanisms respond to changes in leptin concentrations in the low physiological range). The present study does not, however, exclude the possibility that dexamethasone inhibits the ability of leptin to signal satiety (44) or that pregnancy is a 'leptin resistant' state with respect to appetite control $(3,16)$. Increased plasma leptin concentrations evoked by maternal dexamethasone treatment were associated with complete abrogation of maternal body weight gain during the last third of pregnancy. Visual inspection of the dams at the time of sampling suggested a decline in maternal fat mass (although this was not quantified). The present experiments do not indicate whether impaired weight gain was a direct action of dexamethasone or of changes secondary to effects of dexamethasone. However, impaired weight gain was apparent even at the lowest dexamethasone dose at which maternal leptin concentrations were only slightly increased, suggesting that leptin itself is not responsible.

In the non-pregnant state, adipose tissue is the major site of leptin production $(1,45)$ and leptin concentrations correlate with body mass index (46). However, leptin concentrations during pregnancy are increased to an extent that cannot be attributed to an increased body mass index $(5,9)$. Northern and western analysis have demonstrated leptin mRNA and leptin protein in placentas from a wide range of species, despite the different forms of placentation (10, 47), highlighting the possibility that the placenta might contribute to leptin production during pregnancy. In pregnant women, leptin is synthesised in and secreted from placental trophoblasts into the maternal and fetoplacental circulation (48). Moreover, studies with cultured human placenta cells, WSH (amnion) and JEG3 (trophoblast) cells, have shown effects of dexamethasone to increase leptin production by more than twofold (49). In contrast, some studies have failed to detect the presence of leptin in the rat placenta (8) and in rodents, unlike humans, the placenta may not be the major source of maternal leptin production (7). Indeed, in mice, hyperleptinaemia during pregnancy primarily results from corticosterone-dependent up-regulation of leptin secretion from adipose tissue (50). The present study demonstrated protein expression of leptin and ObR-S in the rat placenta near term (day 21, term is 23 days) and demonstrates that placental leptin expression is responsive to glucocorticoid status. It has been suggested that a decrease in fetal nutrient availability towards term may result in a decrease in placental leptin production, in conjunction with an increase in fetal cortisol secretion, thereby leading to the onset of parturition (51). Our data suggest that the glucocorticoid surge characteristic of late gestation may also down-regulate placental leptin production. Taken together, the data suggest that changes in either fetal or maternal leptin may be important for parturition or late fetal development. As the administration of dexamethasone during the last third of pregnancy produced a significant decrease (rather than an increase) in placental leptin expression, our findings would suggest either that leptin secretion from adipose tissue or leptin transport from the placenta is enhanced by glucocorticoids in late pregnancy.

Interestingly, although changes in maternal plasma leptin concentrations do not correlate positively with changes in placental leptin protein expression, placental weight is negatively related to maternal plasma leptin concentrations. Maternal plasma leptin concentrations have been shown previously to correlate negatively with placental weight at term in human pregnancies (11). Pregnancies complicated with intrauterine growth restriction are often associated with increased placental apoptosis (52). The present experiments suggest that a common stimulus to leptin secretion and placental apoptosis may be inappropriately increased maternal glucocorticoid concentrations. Leptin stimulates placental angiogenesis in primary cultures of human endothelial cells (53) and may have a local autocrine immunomodulatory or anti-inflammatory role (54). In view of the finding of leptin receptor protein expression in the rat placenta during late pregnancy, it is not excluded that suppression of placental leptin expression may be a mechanism by which increased glucocorticoids influence placental size through augmenting placental degeneration.

Leptin has been implicated as a potentially important new growth factor in intrauterine and neonatal development (55). Concentrations of leptin in placental and cord blood are often decreased in pregnancies complicated by fetal growth retardation, and increased in those complicated with maternal diabetes (56). In a 33-week twin pregnancy in which one twin was growth retarded and the other a normal size, leptin concentrations in cord blood were lower with the growth-retarded fetus (56). However, it is still not known whether leptin directly regulates fetal growth. In our study, fetal plasma leptin concentrations correlated positively with fetal weights at day 21 of pregnancy. This is consistent with the possibility that fetal leptin acts as a fetal growth factor, and the concept that a 'threshold' level of leptin may be required for optimal fetal growth during normal pregnancy in the rat. Alternatively, factors influencing fetal growth, including glucocorticoids, have a direct effect to regulate fetal leptin concentrations but fetal leptin concentrations themselves do not regulate fetal growth.

The pattern of response of fetal leptin concentrations to dexamethasone treatment (decreased in dexamethasone-treated dams) was the opposite of those of the dams (increased in dexamethasone-treated dams). Thus fetal leptin concentrations do not reflect maternal leptin concentrations (or vice versa). In contrast, maternal dexamethasone treatment decreased both placental leptin expression and fetal leptin concentration. Placenta is a tissue of 'fetal' rather than maternal 
origin. Our findings argue against direct transfer of leptin from the maternal to the fetal circulation in the rat during pregnancy, but are compatible with transfer of leptin from the placenta via ObR-S to the fetus.

In man, associations exist between poor early growth and predisposition to the development of insulin resistance (57-59) and the insulin resistance syndrome (60) in later life. Prenatal exposure to increased glucocorticoids through inhibition of $11 \beta$-HSD-2 by carbenoxolone throughout pregnancy leads both to fetal growth retardation and apparent insulin resistance in adulthood (61). Post-glucose hyperinsulinaemia has been observed previously in the adult male offspring of dexamethasone-treated dams (32). In the setting of insulin resistance and obesity, insulin concentrations typically increase to maintain normal glucose tolerance (62). We examined whether the effect of maternal dexamethasone treatment in elevating circulating insulin concentrations was evident both in adult male and adult female progeny of dexamethasone-treated dams. At 24 weeks of age, insulin concentrations were significantly greater in the male than in female control offspring. In addition, both male and female offspring of dexamethasone-treated dams developed significant ambient hyperinsulinaemia. Thus our data support the concept that exposure to increased glucocorticoids during fetal development 'programmes' the development of hyperinsulinaemia, secondary to insulin resistance, in later life. At 1 year of age, ambient hyperinsulinaemia was maintained in male, but not female, offspring of dexamethasonetreated dams, despite hyperinsulinaemia at periods from 9 to 24 weeks of age in the female group. This pattern is reminiscent of that found in non-insulindependent diabetes mellitus, in which a sustained challenge to the pancreatic $\beta$-cell imposed by insulin resistance ultimately leads to $\beta$-cell exhaustion and, eventually, relative insulin deficiency.

In the non-pregnant state, leptin expression in adipose tissue of lean rodents changes in parallel with the changes in insulin concentrations associated with feeding and fasting (reviewed in 3). In starved rats, it also increases with insulin infusion at euglycemia (63). Plasma leptin concentrations and mRNA are also increased in patients with insulinoma $(36,37)$. A recent study examining the relationship between birth weight and leptin concentrations in a population-based study demonstrated that, at any given level of adult obesity, people of lower birth weight tended to have higher concentrations of leptin than those of greater birth weight (19). It was suggested that this might be a consequence of sustained hyperinsulinaemia. The rat model used in the present study induces hyperinsulinaemia in the male, but not female, offspring at 1 year of age. Although sexual dimorphism in plasma leptin concentrations were clearly detectable in postpubertal offspring - in rats, unlike man, leptin concentrations are generally greater in males than in females (64) - maternal dexamethasone treatment increased ambient leptin concentrations in both male and female offspring of dexamethasone-treated dams at 1 year of age. Thus our data suggest that antecedent hyperinsulinaemia may be permissive for or associated with the development of hyperleptinaemia, but that ambient increased insulin concentrations per se are not obligatory for hyperleptinaemia to be manifest. More importantly, our data extend the association observed between a low birth weight and hyperleptinaemia in adulthood in man.

Hyperleptinaemia during adulthood plays a major part in the development of increased blood pressure in transgenic skinny mice (39). Furthermore, leptin administration reverses the otherwise decreased blood pressure of leptin-deficient $o b / o b$ mice (39). KKA ${ }^{y}$ mice, which are obese and hyperleptinaemic, also exhibit increased blood pressures (39). Thus, hyperleptinaemia is a common feature of both obesity-related and obesity-unrelated hypertension in mice. The present study demonstrates that leptin concentrations are suppressed during fetal life, but increased in adulthood in a rat model of programmed hypertension. Our data suggest that hyperleptinaemia may, therefore, be a component of the cluster of metabolic abnormalities seen in the insulin resistance syndrome in man, and suggest that a common early-life stimulus to the association between hyperinsulinaemia, hypertension and hyperleptinaemia often seen in individuals of low birth weight $(19,60)$ could be fetal exposure to excessively high glucocorticoid concentrations.

\section{Acknowledgements}

We are grateful to the Wellcome Trust (060965/Z/00) and the British Heart Foundation (FS/97079) for financial support. M L L was a recipient of a British Heart Foundation Studentship.

\section{References}

1 Zhang Y, Proenca R, Maffei M, Barone M, Leopold L \& Friedman JM. Positional cloning of the mouse obese gene and its human homologue. Nature 1994372 425-432.

2 Campfield LA, Smith FJ, Guisez Y, Devos R \& Burn P. Recombinant mouse OB protein: evidence for a peripheral signal linking adiposity and central neural networks. Science 1995269 546-549.

3 Holness MJ, Munns MJ \& Sugden MC. Current concepts concerning the role of leptin in reproductive function. Molecular and Cellular Endocrinology 1999157 11-20.

4 Tartaglia LA, Dembski M, Weng X, Deng N, Culpepper J, Devos R et al. Identification and expression cloning of a leptin receptor, OB-R. Cell 199583 1263-1271.

5 Hardie L, Trayhurn P, Abramovich D \& Fowler P. Circulating leptin in women: a longitudinal study in the menstrual cycle and during pregnancy. Clinical Endocrinology 199747 101-106.

6 Masuzaki H, Ogawa Y, Sagawa N, Hosoda K, Matsumoto T, Mise H et al. Nonadipose tissue production of leptin: leptin as a novel placenta-derived hormone in humans. Nature Medicine 19973 1029-1033. 
7 Kawai M, Yamaguchi M, Murakami T, Shima K, Murata Y \& Kishi K. The placenta is not the main source of leptin production in pregnant rat: gestational profile of leptin in plasma and adipose tissues. Biochemical and Biophysical Research Communications 1997240 798-802.

8 Tomimatsu T, Yamaguchi M, Murakami T, Ogura K, Sakata M, Mitsuda $\mathrm{N}$ et al. Increase of mouse leptin production by adipose tissue after midpregnancy: gestational profile of serum leptin concentration. Biochemical and Biophysical Research Communications $1997240213-215$.

9 Chien EK, Hara M, Rouard M, Yano H, Phillippe M, Polonsky KS et al. Increase in serum leptin and uterine leptin receptor messenger RNA levels during pregnancy in rats. Biochemical and Biophysical Research Communications 1997237 476-480.

10 Hoggard N, Hunter L, Duncan JS, Williams LM, Trayhurn P \& Mercer JG. Leptin and leptin receptor mRNA and protein expression in the murine fetus and placenta. PNAS 199794 11073-11078.

11 Schubring C, Kiess W, Englaro P, Rascher W, Dotsch J, Hanitsch S et al. Levels of leptin in maternal serum, amniotic fluid, and arterial and venous cord blood: relation to neonatal and placental weight. Journal of Clinical Endocrinology and Metabolism 199782 1480-1483.

12 Koistinen HA, Koivisto VA, Andersson S, Karonen SL, Kontula K, Oksanen L et al. Leptin concentration in cord blood correlates with intrauterine growth. Journal of Clinical Endocrinology and Metabolism 199782 3328-3330.

13 Jaquet D, Leger J, Levy-Marchal C, Oury JF \& Czernichow P. Ontogeny of leptin in human fetuses and newborns: effect of intrauterine growth retardation on serum leptin concentrations. Journal of Clinical Endocrinology and Metabolism 199883 12431246.

14 Ong KK, Ahmed ML, Sherriff A, Woods KA, Watts A, Golding J et al. Cord blood leptin is associated with size at birth and predicts infancy weight gain in humans. ALSPAC Study Team. Avon Longitudinal Study of Pregnancy and Childhood. Journal of Clinical Endocrinology and Metabolism 199984 1145-1148.

15 Mounzih K, Lu R \& Chehab FF. Leptin treatment rescues the sterility of genetically obese ob/ob males. Endocrinology 1997 138 1190-1193.

16 Mounzih K, Qiu J, Ewart-Toland A \& Chehab FF. Leptin is not necessary for gestation and parturition but regulates maternal nutrition via a leptin resistance state. Endocrinology 1998139 5259-5262.

17 Hoggard N, Hunter L, Lea RG, Trayhurn P \& Mercer JG. Ontogeny of the expression of leptin and its receptor in the murine fetus and placenta. British Journal of Nutrition 200083 317-326.

18 Gavrilova O, Barr V, Marcus-Samuels B \& Reitman M. Hyperleptinemia of pregnancy associated with the appearance of a circulating form of the leptin receptor. Journal of Biological Chemistry 1997272 30546-30551.

19 Phillips DI, Fall CH, Cooper C, Norman RJ, Robinson JS \& Owens PC. Size at birth and plasma leptin concentrations in adult life. International Journal of Obesity and Related Metabolic Disorders 199923 1025-1029.

20 Lissner L, Karlsson C, Lindroos AK, Sjostrom L, Carlsson B, Carlsson L et al. Birth weight, adulthood BMI, and subsequent weight gain in relation to leptin levels in Swedish women. Obesity Research 19997 150-154.

21 Yuen BS, McMillen IC, Symonds ME \& Owens PC. Abundance of leptin mRNA in fetal adipose tissue is related to fetal body weight. Journal of Endocrinology 1999163 R11-R14.

22 Holness MJ \& Sugden MC. Suboptimal protein nutrition in early life later influences insulin action in pregnant rats. Diabetologia $19963912-21$.

23 Sohlstrom A, Katsman A, Kind KL, Roberts CT, Owens PC, Robinson IS et al. Food restriction alters pregnancy-associated changes in IGF and IGFBP in the guinea pig. American Journal of Physiology (Endocrinology and Metabolism) 1998274 E410E416.
24 Harding JE \& Johnston BM. Nutrition and fetal growth. Reproduction Fertility and Development 19957 539-547.

25 Eckert JE, Gatford KL, Luxford BG, Campbell RG \& Owens PC. Leptin expression in offspring is programmed by nutrition in pregnancy. Journal of Endocrinology 2000165 R1-R6.

26 Fowden AL, Li J \& Forhead AJ. Glucocorticoids and the preparation for life after birth: are there long-term consequences of the life insurance? Proceedings of the Nutrition Society 199857 $113-122$

27 Holness MJ. Langdown ML \& Sugden MC. Early-life programming of susceptibility to dysregulation of glucose metabolism and the development of Type 2 diabetes mellitus. Biochemical Journal $2000349657-665$

28 Seckl JR, Cleasby M \& Nyirenda MJ. Glucocorticoids, 11betahydroxysteroid dehydrogenase, and fetal programming. Kidney International $2000 \mathbf{5 7} 1412-1417$.

29 Goland RS, Jozak S, Warren WB, Conwell IM, Stark RI \& Tropper PJ. Elevated levels of umbilical cord plasma corticotropin-releasing hormone in growth-retarded fetuses. Journal of Clinical Endocrinology and Metabolism 199377 1174-1179.

30 Brown RW, Chapman KE, Kotelevtsev Y, Yau JL, Lindsay RS, Brett L et al. Cloning and production of antisera to human placental 11 beta-hydroxysteroid dehydrogenase type 2. Biochemical Journal 1996313 1007-1017.

31 Albiston AL, Obeyesekere VR, Smith RE \& Krozowski ZS. Cloning and tissue distribution of the human 11 beta-hydroxysteroid dehydrogenase type 2 enzyme. Molecular and Cellular Endocrinology 1994105 R11-R17.

32 Nyirenda MJ, Lindsay RS, Kenyon CJ, Burchell A \& Seckl JR. Glucocorticoid exposure in late gestation permanently programs rat hepatic phosphoenolpyruvate carboxykinase and glucocorticoid receptor expression and causes glucose intolerance in adult offspring. Journal of Clinical Investigation 19981012174 2181.

33 Levitt NS, Lindsay RS, Holmes MC \& Seckl JR. Dexamethasone in the last week of pregnancy attenuates hippocampal glucocorticoid receptor gene expression and elevates blood pressure in the adult offspring in the rat. Neuroendocrinology 1996 64 412-418.

34 Boden G, Chen X, Kolaczynski JW \& Polansky M. Effects of prolonged hyperinsulinemia on serum leptin in normal human subjects. Journal of Clinical Investigation 1997100 1107-1113.

35 Kolaczynski JW, Nyce MR, Considine RV, Boden G, Nolan JJ, Henry $\mathrm{R}$ et al. Acute and chronic effects of insulin on leptin production in humans: studies in vivo and in vitro. Diabetes 1996 45 699-701.

36 D'Adamo M, Buongiorno A, Maroccia E, Leonetti F, Barbetti F, Giaccari A et al. Increased OB gene expression leads to elevated plasma leptin concentrations in patients with chronic primary hyperinsulinemia. Diabetes 199847 1625-1629.

37 Popovic V, Micic D, Danjanovic S, Zoric S, Djurovic M, Obradovic S et al. Serum leptin and insulin concentrations in patients with insulinoma before and after surgery. European Journal of Endocrinology 1998138 86-88.

38 Haynes WG. Interaction between leptin and sympathetic nervous system in hypertension. Current Hypertension Reports 20002 311-318.

39 Aizawa-Abe M, Ogawa Y, Masuzaki H, Ebihara K, Satoh N, Iwai H et al. Pathophysiological role of leptin in obesity-related hypertension. Journal of Clinical Investigation $20001051243-$ 1252.

40 Adamczak M, Kokot F \& Wiecek AW. Relationship between plasma renin profile and leptinaemia in patients with essential hypertension. Journal of Human Hypertension 200014 503-509.

41 Lederman SA \& Rosso P. Effects of fasting during pregnancy on maternal and fetal weight and body composition in wellnourished and undernourished rats. Journal of Nutrition 1981 111 1823-1832.

42 Benediktsson R, Lindsay RS, Noble J, Seckl JR \& Edwards CR. Glucocorticoid exposure in utero: new model for adult hypertension. Lancet 1993341 339-341. 
43 Madiehe AM, Schaffhauser AO, Braymer DH, Bray GA \& York DA. Differential expression of leptin receptor in high- and low-fat-fed Osborne-Mendel and S5B/Pl rats. Obesity Research 20008 467474.

44 Jeanrenaud B \& Rohner-Jeanrenaud F. CNS-periphery relationships and body weight homeostasis: influence of the glucocorticoid status. International Journal of Obesity and Related Metabolic Disorders 200024 (Suppl 2) S74-S76.

45 Auwerx J \& Staels B. Leptin. Lancet 1998351 737-742.

46 Kennedy A, Gettys TW, Watson P, Wallace P, Ganaway E, Pan Q et al. The metabolic significance of leptin in humans: genderbased differences in relationship to adiposity, insulin sensitivity, and energy expenditure. Journal of Clinical Endocrinology and Metabolism 199782 1293-1300.

47 Senaris R, Garcia-Caballero T, Casabiell X, Gallego R, Castro R, Considine RV et al. Synthesis of leptin in human placenta. Endocrinology 1997138 4501-4504.

48 Yura S, Sagawa N, Ogawa Y, Masuzaki H, Mise H, Matsumoto T et al. Augmentation of leptin synthesis and secretion through activation of protein kinases $\mathrm{A}$ and $\mathrm{C}$ in cultured human trophoblastic cells. Journal of Clinical Endocrinology and Metabolism 199883 3609-3614.

49 Soh EB, Mitchell MD \& Keelan JA. Does leptin exhibit cytokinelike properties in tissues of pregnancy? American Journal of Reproduction and Immunology 200043 292-298.

50 Kronfeld-Schor N, Zhao J, Silvia BA, Bicer E, Mathews PT, Urban $\mathrm{R}$ et al. Steroid-dependent up-regulation of adipose leptin secretion in vitro during pregnancy in mice. Biology of Reproduction $200063274-280$.

51 Symonds ME, Heasman L, Clarke L, Firth K \& Stephenson T. Maternal nutrition and disproportionate placental-to-fetal growth. Biochemical Society Transactions 199826 91-96.

52 Smith SC, Baker PN \& Symonds EM. Increased placental apoptosis in intrauterine growth restriction. American Journal of Obstetrics and Gynecology 1997177 1395-1401.

53 Sierra-Honigmann MR, Nath AK, Murakami C, GarciaCardena G, Papapetropoulos A, Sessa WC et al. Biological action of leptin as an angiogenic factor. Science $1998 \mathbf{2 8 1} 1683-1686$.

54 Takahashi N, Waelput W \& Guisez Y. Leptin is an endogenous protective protein against the toxicity exerted by tumor necrosis factor. Journal of Experimental Medicine 1999189 207-212.
55 Hassink SG, de Lancey E, Sheslow DV, Smith-Kirwin SM, O'Connor DM, Considine RV et al. Placental leptin: an important new growth factor in intrauterine and neonatal development? Pediatrics $1997 \mathbf{1 0 0}$ E1.

56 Lea RG, Howe D, Hannah LT, Bonneau O, Hunter L \& Hoggard N. Placental leptin in normal, diabetic and fetal growth-retarded pregnancies. Molecular Human Reproduction 20006 763-769.

57 Phillips DI. Insulin resistance as a programmed response to fetal undernutrition. Diabetologia 199639 1119-1122.

58 McKeigue PM, Lithell HO \& Leon DA. Glucose tolerance and resistance to insulin-stimulated glucose uptake in men aged 70 years in relation to size at birth. Diabetologia $1998 \mathbf{4 1} 1133-$ 1138.

59 Clausen JO, Borch-Johnsen K \& Pedersen O. Relation between birth weight and the insulin sensitivity index in a population sample of 331 young, healthy Caucasians. American Journal of Epidemiology 1997146 23-31.

60 Barker DJP, Hales CN, Fall CH, Osmond C, Phipps K \& Clark PM. Type 2 (non-insulin-dependent) diabetes mellitus, hypertension and hyperlipidaemia (syndrome $\mathrm{X}$ ): relation to reduced fetal growth. Diabetologia $19933662-67$.

61 Lindsay RS, Lindsay RM, Waddell BJ \& Seckl JR. Prenatal glucocorticoid exposure leads to offspring hyperglycaemia in the rat: studies with the 11 beta-hydroxysteroid dehydrogenase inhibitor carbenoxolone. Diabetologia 199639 1299-1305.

62 Cavaghan MK, Ehrmann DA \& Polonsky KS. Interactions between insulin resistance and insulin secretion in the development of glucose intolerance. Journal of Clinical Investigation 2000 $106329-333$.

63 Saladin R, De Vos P, Guerre-Millo M, Leturque A, Girard J, Staels B et al. Transient increase in obese gene expression after food intake or insulin administration. Nature 1995377 527-529.

64 Landt M, Gingerich RL, Havel PJ, Mueller WM, Schoner B, Hale JE et al. Radioimmunoassay of rat leptin: sexual dimorphism reversed from humans. Clinical Chemistry $1998 \mathbf{4 4}$ 565-570.

Received 18 October 2000

Accepted 15 June 2001 